\title{
UNA COMPARACIÓN \\ DE LA EXPERIENCIA DE CINCO IMPORTANTES PAÍSES DE EMIGRACIÓN
}

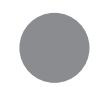

STEPHEN CASTLES

TRADUCCIÓN DE LUIS RODOLFO MORÁN QUIROZ

Resumen. Este apartado resume y compara los hallazgos del estudio de los cinco países de emigrantes -India, México, Marruecos, Filipinas y Turquía- estudiados en este volumen. Discute el alcance con el que estos cinco países comparten características significativas comunes, de tal modo que el análisis comparativo podría proporcionar elementos útiles del proceso migratorio. El artículo retoma el debate sobre migración y desarrollo que ha sido tan prominente en círculos internacionales de definición de políticas. Por ello, se hace un esfuerzo para examinar el punto en el cual la migración ha realmente contribuido al desarrollo en los cinco países de origen estudiados. La conclusión general es que la migración es resultado de procesos sociales de transformación ligados con la globalización y el re-ordenamiento de las relaciones económicas y políticas postcoloniales. De manera continua, la migración se convierte en un factor en los sucesivos procesos de transformación. De esta manera, la migración debería de incluirse en estrategias para alcanzar el cambio, aunque las condiciones para alcanzar resultados positivos son complejas y difíciles. Las estrategias de «desarrollo guiado por remesas» parecen simplistas e infantiles. La migración por sí misma no puede remover las limitaciones estructurales para el crecimiento económico sostenido. Hay una necesidad de enfoques de base amplia y de largo plazo que ligue, el beneficio potencial de la migración, con estrategias más generales para reducir la desigualdad y mejorar la infraestructura económica, el bienestar social y la governanza política.

Palabras ClaVe. Migración, desarrollo, transformación social, remesas, diásporas, retorno.

Aвstract. This chapter summarizes and compares the findings of the studies of five major emigration countries - India, Mexico, Morocco, the Philippines and Turkey- presented in this issue. It discusses the extent to which the five countries share significant common characteristics, so that a comparative analysis may provide useful insights into migratory processes. The chapter takes up the debate on migration and development that has become so prominent in international policy circles. An attempt is made to examine the extent to which migration has actually contributed to development in the five countries of origin. The general conclusion is that migration is itself a result of processes of social transformation linked to globalization and the post-colonial re-ordering of economic and political relationships. In turn, migration becomes a factor in further processes of transformation. Thus migration should be included in strategies for achieving change, but the conditions for realizing positive results are complex and difficult. Strategies of «remittance-led development» seem simplistic and naïve. Migration alone cannot remove structural constraints to sustainable economic growth. There is a need for broadly-based long-term approaches that links the potential benefits of migration with more general strategies to reduce inequality and to improve economic infrastructure, social welfare and political governance.

KEYwoRDs. Migration, development, social transformation, remittances, diasporas, return. 


\section{INTRODUCCIÓN}

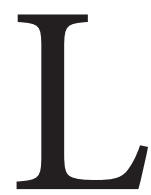

os estudios que presentamos en este número de Migración y desarrollo analizan cinco países que se cuentan entre los principales emisores de migrantes en el mundo. Aportan datos relevantes sobre la experiencia de los migrantes y sus comunidades. De manera más amplia, nos ayudan a entender las complejas relaciones entre el cambio global, la migración y el desarrollo. Los estudios muestran la diversidad y la complejidad de la experiencia migratoria, así como la manera en que ésta transforma vidas y construye lazos duraderos por encima de las fronteras nacionales. El propósito de este trabajo comparativo es aprovechar dichos ejercicios analíticos para identificar diferencias y similitudes en la experiencia migratoria y sus efectos en las sociedades involucradas, así como las relaciones con los países de inmigración. ${ }^{1}$

Esto plantea la siguiente pregunta: ¿resulta útil la comparación sugerida, en vista de las importantes diferencias entre los cinco países en términos de historia, cultura, desarrollo económico y relaciones internacionales? Sin lugar a dudas, se podría ir más allá y preguntar: ¿es posible esa comparación, si las diferencias son tan grandes? Este ensayo comparativo pretende dar una respuesta a esas preguntas. Un primer objetivo es ver si estos países comparten características comunes significativas de modo que los analistas, diseñadores de políticas y actores prácticos puedan encontrar reflexiones de importancia a partir de la comparación. Otro tema sustancial se relaciona con el nuevo discurso sobre la migración y el desarrollo que se ha tornado tan prominente en los círculos de políticas internacionales en los años recientes. Una de las principales tareas del estudio de los países es examinar en qué medida la migración contribuye al desarrollo. Un segundo objetivo es sintetizar la diversa evidencia sobre migración y desarrollo e intentar generalizar a partir de ella.

\section{LAS FUERZAS DETRÁS}

\section{DE LA EMIGRACIÓN}

¿Qué hace que la gente deje sus países en busca de una vida mejor en el extranjero? Es posible sintetizar las razones bajo los encabezados de demografía, economía —o mejor aún: economía política- y política.

Los cinco países varían considerablemente en cuanto al tamaño de su población: desde 31 millones en Marruecos, hasta las muy considerables poblaciones de Turquía (73 millones), Filipinas (83 millones) y México (107 millones), mientras que India, con

\footnotetext{
${ }^{1}$ Este trabajo se basa en los cinco estudios presentados en el presente número de Migración y desarrollo. Por lo tanto no puede considerarse como resultado de una investigación original. Agradezco a los autores de los cinco estudios nacionales por permitirme utilizar su trabajo. Las interpretaciones son responsabilidad mía. Mi texto no reitera la referencia a los estudios por país (a menos que los cite directamente) ni a sus fuentes.
} 
mil cien millones de personas en 2005, es uno de los dos grandes gigantes en términos poblacionales (Un Population Division, 2006). Lo que los une es que su «transición demográfica» es relativamente reciente, al pasar de patrones de alta fecundidad y mortalidad, típicos de los países agrarios menos desarrollados, hacia patrones con una mortalidad rápidamente en declive, una creciente expectativa de vida y un crecimiento poblacional acelerado como consecuencia de la modernización. Los cinco países han verificado un cuantioso ingreso de jóvenes a su fuerza de trabajo. Se han complementado con las tendencias demográficas en los países altamente desarrollados que importan mano de obra, donde la fecundidad ha descendido marcadamente, la expectativa de vida se ha incrementado todavía más y las tasas de dependencia por edad (razón de personas jubiladas frente a las personas en edad de trabajar) han crecido rápidamente. La fecundidad también está en declive en los cinco países - aunque en menor medida en India y Filipinas-, de modo que el crecimiento de la población llegará a su máximo en un futuro cercano. Los países estudiados han sido importantes reservas de mano de obra para las economías más ricas, pero pueden dejar de serlo, aproximadamente, entre el 2025 y el 2050. Ello podría significar una caída de la migración e incluso flujos inversos en el futuro, o podría adoptar la forma que se ha dado en México: despoblamiento de las áreas rurales, hasta el punto en que se bloquea el desarrollo futuro.

La demografía siempre constituye apenas un lado de la imagen de la migración. ¿Por qué las economías no han crecido lo suficientemente rápido como para ofrecer empleo a las nuevas generaciones laborales? Los cinco países estudiados denotan un bloqueo en materia de desarrollo e, incluso, un desarrollo económico desigual. En los casos de India y México, se hace referencia al fracaso de estrategias pasadas, la industrialización para sustitución de importaciones, es decir, el desarrollo de la industria nacional mediante barreras tarifarias. En India, esta estrategia generó un gran sector estatal y altos niveles de regulación que generaron estancamiento, bajo crecimiento, escasas exportaciones, salarios bajos y falta de empleos para trabajadores calificados o sin calificación. En Turquía, la ineficiencia estatal, el conflicto político y étnico, la poca infraestructura y la corrupción tuvieron efectos similares. En la década de los sesenta, muchos esperaban de Filipinas que se situara al borde del «despegue económico», debido a su alto nivel de escolaridad y sus buenas conexiones internacionales. Esta esperanza se canceló por una mezcla de dictadura — el régimen de Marcos—, inestabilidad política y falta de inversión extranjera directa (IED), quizá este último factor fuera consecuencia de los primeros.

Más recientemente, las estrategias neoliberales del «Consenso de Washington» para la liberalización de los mercados de capital y de mercancías, la privatización de la industria y los servicios, junto con las reducciones en el gasto social, han llevado a cierto grado de estabilización económica, pero no han generado suficientes empleos. Por el contrario, el ajuste estructural puede ser, en sí mismo, un factor que reduzca el empleo y estimule la emigración (Adepoju, 2006). El texto sobre el caso mexicano hace notar que la aprobación del Tratado de Libre Comercio de América del Norte (TLCAN) ha sido el fundamento de la integración neoliberal de las economías mexicana y estadounidense, que ha beneficiado exclusivamente a esta última. El sistema de maquiladoras, con plantas que producen para el mercado apenas cruzando la frontera con México, ha ubicado 
a la mano de obra barata mexicana al servicio de las compañías estadounidenses, sin hacer cosa alguna por reducir la migración hacia el norte.

De ahí que la economía política de la emigración haya sido bastante similar. Tres de los cinco países han experimentado control colonial directo en tiempos recientes: India por Gran Bretaña, Marruecos por Francia y Filipinas por Estados Unidos. Dos han sido sujetos a poderosas influencias semicoloniales: México por Estados Unidos, a partir del siglo XIX, y Turquía por los poderes centrales europeos, en especial Alemania, desde principios del siglo xx. En el periodo posterior a 1945, los cinco países han experimentado un dominio económico bajo formas sucesivas de neocolonialismo, control multinacional de la agricultura y la industria y, más recientemente, de la globalización. Los resultados han sido desarrollo desigual, empobrecimiento de ciertos grupos, migración rural-urbana y migración constante hacia países industriales.

En algunos de los países, la política ha jugado un papel aún más directo. La monarquía autocrática de Marruecos, de los años cincuenta y sesenta, veía a la emigración como una válvula de escape del descontento, en especial entre los berebere (que constituyen una gran parte de la población marroquí). Como señala De Haas (en este volumen), la mayor parte de la emigración provenía de la parte oriental de las montañas del Rif y de otras regiones predominantemente berebere. La dictadura de Marcos en Filipinas comenzó un programa sistemático de exportación de mano de obra, en parte con la esperanza de reducir el descontento hacia el carácter predatorio del régimen y su incapacidad para mejorar los estándares de vida de las masas. La emigración turca ha estado ligada tanto con el conflicto político como con el conflicto étnico. Desde los años sesenta hasta los ochenta, muchos emigrantes trataban de escapar de los sucesivos regímenes militares y su control de los sindicatos y las organizaciones democráticas. Desde los años noventa, muchos de los emigrantes y los solicitantes de asilo eran de etnia kurda y buscaban refugiarse de la violencia y la persecución en torno al conflicto entre el Estado turco y los nacionalistas kurdos.

\section{LA MIGRACIÓN Y LA TRANSFORMACIÓN SOCIAL}

Las contradicciones de la globalización están reconfigurando tanto los patrones reales de migración como las percepciones públicas de ésta. Debido a la constante reiteración que hacen gobiernos y agencias internacionales, la noción de desarrollo parece haber asumido un carácter de «afirmación de sentido común», una afirmación que supuestamente no requiere explicación o justificación. Argumentamos a favor de la necesidad de cuestionar este «sentido común», en especial en el contexto de «la migración y el desarrollo». Con frecuencia se equipara, tácitamente, al desarrollo con el cambio positivo, en el sentido teleológico de emulación de modelos occidentales exitosos de crecimiento económico, junto con las instituciones sociales y políticas así como los valores que parecen sostenerlos. Pero es frecuente que se olvide que la precondición para las revoluciones industriales, en Europa y América del Norte, fue la transferencia forzada de recursos provenientes del resto del mundo durante la época colonial. El control de los recursos, 
de la fuerza de trabajo y la habilidad para trasladarlos a donde se les necesitara, para la acumulación de capital, constituyeron aspectos cruciales de la modernización.

Los factores que impulsan la emigración son parte, pues, de amplios procesos de transformación social que han afectado a las sociedades de África, Asia y América Latina, al ser incluidas en el sistema económico y político mundial generado por la dominación cultural y tecnológica de Europa occidental y Estados Unidos desde el siglo XVI (Castles, 2007). Las etapas de este proceso han incluido el colonialismo, el imperialismo, la descolonización, el neocolonialismo y, ahora, la globalización. Una condición previa necesaria para el desarrollo del norte ha sido el subdesarrollo del sur, por medio de la transferencia de recursos críticos hacia el primero. El control de la mano de obra de los países del sur, por los Estados y capitales del norte, siempre ha sido parte de esta transacción, ya sea en forma de esclavitud, trabajo forzado en las plantaciones o reclutamiento para las minas (Rodney, 1972). La transferencia de fuerza de trabajo y habilidades hacia los países ricos, por medio de la migración laboral, es la forma más reciente de ayuda para el desarrollo que el sur aporta al norte, así que es posible preguntarse por qué los Estados y las agencias internacionales lo plantean como un factor importante en el desarrollo de los países de origen. Si la migración beneficiara a los países de origen, habría que cumplir con importantes condiciones con respecto al intercambio justo, la salvaguarda de los derechos humanos y la transferencia de recursos hacia los lugares de origen de los migrantes.

La globalización y la transformación social llevan a nuevas formas de incorporación en el mercado laboral en diversos ámbitos espaciales. La penetración de las economías del sur, por el capital global, genera la reestructuración de los procesos de producción, dentro de los cuales se incluyen algunos productores que experimentan ingresos más altos, mientras que otros grupos se encuentran con que sus puestos de trabajo acaban por ser eliminados y sus habilidades se devalúan. Decae la agricultura de subsistencia, mientras que la producción de cultivos impulsada por los mercados y orientada hacia la ganancia requiere considerables insumos de capital, lo que lleva a la concentración de la tenencia de la tierra en manos de los grandes terratenientes (los que, a su vez, dependen de los gigantes multinacionales de los negocios agrícolas, el agribusiness). Los trabajadores rurales desplazados migran a los pueblos, alimentando los crecientes megacinturones de miseria de África, Asia y América Latina. Los bajos salarios y la falta de verdaderos empleos hacen que la vida sea precaria y riesgosa para estos nuevos habitantes de las ciudades. En muchos casos, el empobrecimiento se complica con la corrupción, la violencia y la represión de los regímenes débiles y dictatoriales. El fracaso en la incorporación de los migrantes de las zonas rurales hacia las urbanas, en las sociedades y los mercados de fuerza de trabajo de las ciudades, acaba por dejar a la migración transfronteriza como la forma obvia de escape.

Buena parte de esta migración económica es desde el sur hacia el sur: por ejemplo, los egipcios y marroquíes hacia Libia, rica en petróleo, de los mozambiqueños hacia Sudáfrica o de filipinos hacia Malasia. Otra porción de la migración regional es forzada, en busca de protección: de Burundi a Tanzania, de tibetanos a India, de colombianos a Venezuela. Buena parte de la migración implica «motivaciones mixtas», gente que 
huye de la persecución y en busca de mejoría económica. Sin embargo, una creciente proporción la constituye la migración del sur al norte. Ésta puede ser de alcance regional o global. Los mercados regionales de mano de obra son significativos para México, con una migración predominantemente hacia el vecino país del norte; para Marruecos, cuyos trabajadores solían ir principalmente a Francia y Holanda, así como, más recientemente, a España e Italia; lo mismo para Turquía, con traslados, en el pasado, hacia Alemania y Holanda, además de una movilidad actual hacia los países petroleros del Golfo. En contraste, los emigrantes indios y filipinos están dispersos por el globo en numerosos destinos. Los indios altamente calificados se trasladan, principalmente, a Estados Unidos, pero también a Canadá, Australia, Reino Unido y otros países europeos. Los de menor capacitación van hacia el Golfo, pero también a Europa, Japón, Singapur y Malasia. Los migrantes de Filipinas se encuentran en todos los países altamente desarrollados, pero también en el Golfo y los países recientemente industrializados de Asia y Japón. Las trabajadoras domésticas filipinas son ubicuas, mientras que los marineros filipinos tripulan barcos con distintas banderas nacionales. Como señala el estudio de Filipinas (en este volumen), los funcionarios en ese país lo muestran con orgullo como el «productor de trabajadores para el mundo». ${ }^{2}$

\section{HISTORIA DE LA MIGRACIÓN}

Sólo cerca del 3\% de la población mundial es migrante internacional, pero la migración es desigual: ciertos países se han convertido en importantes lugares de origen de los migrantes. ¿Qué convierte a un país en reservorio de mano de obra para los países desarrollados? En la mayoría de los casos, esto no se da por un cambio súbito, sino que es, en realidad, la culminación de largos procesos históricos. La migración no es un fenómeno nuevo: todos los países tratados aquí tuvieron patrones premodernos de movilidad temporal con propósitos agrícolas, comerciales, culturales o religiosos y de traslados más permanentes como consecuencia de guerras, factores económicos o cambio económico. Empero, fue el colonialismo el que preparó el camino para los movimientos migratorios modernos. Los gobiernos coloniales convirtieron a India en una fuente primordial de trabajadores y soldados bajo contrato, por el tiempo que le quedaba al imperio británico en el siglo xIx (Cohen, 1995). La migración marroquí a Francia comenzó con el reclutamiento colonial de trabajadores para cavar trincheras y reemplazar a los trabajadores franceses reclutados para el ejército en la Primera Guerra

\footnotetext{
${ }^{2}$ En el estudio de Marruecos, De Haas llama la atención a la «perspectiva de sistemas migratorios» como una forma de analizar la migración internacional (véase también Kritz et al., 1992). Sin entrar aquí en detalle, esa aproximación parece ajustarse mejor a los sistemas regionales que afectan México, Marruecos y Turquía. Es más difícil de aplicar a los espacios en donde los migrantes de un lugar de origen se dispersan en alto grado, como sucede con los indios y filipinos. No obstante, un análisis detallado de los componentes específicos de estas migraciones - por ejemplo, los profesionistas indios de la industria electrónica en California o el personal médico filipino en Reino Unido, o las mujeres dedicadas a la industria del entretenimiento en Japón- bien podría beneficiarse del marco de los sistemas migratorios.
} 
Mundial. Los patrones de Estados Unidos reclutaron trabajadores, en Filipinas, para las plantaciones de Hawai desde principios del siglo xx. En su forma moderna, México es producto de la colonización del Nuevo Mundo. Más recientemente, el estudio mexicano llama la atención a una sucesión de etapas de «migración neocolonial» basadas en el dominio económico de Estados Unidos desde fines del siglo xIx.

En cierto modo, Turquía constituye una excepción: en el periodo del imperio otomano era un área de inmigración y atraía tanto a migrantes económicos (por ejemplo, mercaderes genoveses) como a minorías religiosas perseguidas (por ejemplo, judíos sefarditas en el siglo xvI). La emigración turca estuvo vinculada con las necesidades militares y administrativas del imperio otomano. El establecimiento del Estado-nación turco, después de la Primera Guerra Mundial, condujo a la inmigración de personas de ascendencia turca y musulmana provenientes de la región aledaña. La emigración laboral a gran escala no comenzó sino hasta los años sesenta y fue consecuencia de la acción estatal, bajo la guisa del deseo de las autoridades laborales, alemanas y holandesas, de reclutar trabajadores y la ambición del gobierno turco por encontrar un paliativo al desempleo. Ello apunta a la doble causalidad de la migración laboral contemporánea. La migración india hacia Gran Bretaña fue resultado tanto de la falta de oportunidades, en el país de origen, como la fuerte demanda de fuerza de trabajo en las industrias manufactureras del Reino Unido, todavía pujantes en los años cincuenta y sesenta. La fuga de cerebros indios, durante este periodo, también se dio como resultado de la combinación de perspectivas escasas en el lugar de origen y la demanda de especialistas en los países desarrollados.

De igual manera, la migración mexicana a Estados Unidos continuó durante y después de la Segunda Guerra Mundial como efecto del Programa Bracero, propuesto por las autoridades de Estados Unidos para responder a la demanda de mano de obra por parte de los patrones en el sector agrícola a gran escala. La migración marroquí hacia Europa occidental se inició con el reclutamiento de mano de obra hacia Francia, que siguió viejos patrones coloniales, seguido rápidamente por el reclutamiento de «trabajadores huéspedes» hacia Holanda y Alemania. La migración laboral de Filipinas parece haber recibido un ímpetu inicial de las políticas del gobierno, pero luego se tornó en un proceso autogenerado, en donde una fuerte demanda de mano de obra, la buena reputación de los trabajadores filipinos y la continua falta de empleo en el terruño se combinaron para desembocar en el mismo efecto.

Nuevamente, se apunta hacia un patrón: como sea que se hayan iniciado los traslados, tendían a convertirse en autosustentados, debido a una combinación de demanda por los patrones y de dependencia estructural de mano de obra extranjera dentro de las áreas receptoras y una expectativa de movilidad en los países de origen (es decir, «culturas de migración»). Las redes migrantes emergentes jugaron un importante papel en el sostenimiento de la migración, pues hicieron más fácil, para los nuevos migrantes, seguir rutas migratorias establecidas, encontrar empleo y obtener vivienda. Éstas habrían de formar el cimiento de lo que se conocería como «comunidades transnacionales», que son grupos de personas que viven a ambos lados de las fronteras y tienen importantes afiliaciones en más de una sociedad (Portes et al., 1999; Vertovec, 2004). A medida que 
la migración se convirtió en una característica de largo plazo de las relaciones entre las economías de los países menos y más desarrollados, con frecuencia cambio su forma. Aún más importante, la migración laboral tendió a desembocar en la reunificación familiar y el establecimiento permanente. Por lo general, esto iba en contra de los objetivos de los países importadores de mano de obra (Castles, 2004). Las medidas adoptadas para restringir la migración con frecuencia generaron resultados inesperados: cuando Alemania y Francia dejaron de reclutar desde Turquía y Marruecos, en los años setenta, esto llevó a un cambio en los flujos migratorios laborales hacia la reunificación familiar y, en el caso de Turquía y Alemania, a flujos de solicitantes de asilo. De igual manera, el efecto de la militarización de la frontera de Estados Unidos, desde 1994, ha convertido a los residentes temporales en residentes permanentes.

\section{CARACTERÍSTICAS DE}

\section{LA MIGRACIÓN}

Esta sección sintetiza algunas de las principales características de los flujos migratorios y de los migrantes. Se detallan estas características en los estudios por país.

\section{Volumen}

Al finalizar el siglo xx, se calculaba que 20 millones de indios vivían fuera de su país, en la actualidad se estima que esta cifra alcanza los 25 millones, una gran cantidad, pero menos del $2 \%$ de la enorme población de India. El total incluye a los nacidos en el extranjero descendientes de migrantes previos. Las cifras parecen bastante ambiguas, pero, por lo general, se cree que se trata de unos 10 millones de indios no residentes (HNR) - emigrantes con ciudadanía india- y cerca de 10 millones de personas de origen indio ( $\mathrm{POH})$ - personas de la primera y sucesivas generaciones de origen indio que tienen ciudadanía en el extranjero- - El flujo anual de salida, en la actualidad, es de cerca de medio millón.

La abrumadora mayoría de los emigrantes mexicanos se encuentra en Estados Unidos, en donde forman la más grande diáspora del mundo, misma que se calcula en 26.6 millones de personas de origen mexicano, de las cuales, cerca de 10 millones nacieron en México, alrededor del 10\% de la población mexicana. La diáspora incluye a gente con ciudadanía mexicana, los que tienen ciudadanía estadounidense y los de doble ciudadanía. El flujo promedio anual, de México a Estados Unidos, se sitúa en 400,000.

Marruecos es el país de mayor emigración del norte de África, con más de 3 millones de migrantes en Europa, lo que equivale a cerca del $10 \%$ de la población del país. El flujo anual de salida se calcula en cerca de 100,000 personas. ${ }^{3}$ Filipinas tiene unos $8 \mathrm{mi}$ -

\footnotetext{
${ }^{3}$ Comunicación personal de Hein de Haas, septiembre de 2005.
} 
llones de personas en el extranjero, en este caso, también cerca del 10\% de la población. Casi un millón de trabajadores por contrato en el extranjero (TCE) salen cada año.

Casi cuatro millones de personas de origen turco viven en Europa occidental, de los cuales, 2.5 millones está en Alemania. Se calcula que cerca de 1.3 millones de personas de origen turco se han convertido en ciudadanos de la Unión Europea (UE), aunque muchos de ellos tienen la doble ciudadanía. Otros grupos de trabajadores migrantes, principalmente temporales, se encuentran en los países del Golfo. De ahí que el equivalente al $5 \mathrm{o}$ $6 \%$ de la población turca sea emigrante. No obstante, los actuales flujos de salida son relativamente pequeños y puede que sean superados por flujos de tránsito y de inmigración.

\section{Tipos de migrante}

La gran mayoría de los emigrantes de los cinco países han sido migrantes económicos en busca de mejores formas de ganarse la vida. Empero, el movimiento de refugiados y solicitantes de asilo ha sido importante hacia Turquía, y sigue siéndolo con los de la etnia kurda que todavía buscan asilo. Recientemente, algunos musulmanes han huido del sur de Filipinas como refugiados, principalmente a Malasia.

Dentro de la categoría de migrantes económicos hay una gran diversidad. Los indios con alta capacitación -ingenieros, especialistas en tecnología de la información, científicos, administradores - se van a Estados Unidos y a otros países ricos, mientras que los indios con menor capacitación se dirigen principalmente al Golfo. Muchos filipinos altamente calificados encuentran empleo en Estados Unidos y Europa, con frecuencia experimentan una devaluación ocupacional (por ejemplo, de la medicina a la enfermería) en ese proceso. Las trabajadoras domésticas filipinas con frecuencia tienen una alta escolaridad, la que se desperdicia en los empleos de bajos salarios en el extranjero. Los filipinos con habilidades técnicas y de nivel medio encuentran empleo en la construcción, las industrias de procesamiento y en otros sectores en el Golfo. No obstante, la mayoría de los filipinos TCE se trasladan a empleos de baja capacitación en una gran variedad de sectores, incluido el de la marinería. En el pasado, la mayor parte de los mexicanos, marroquíes y turcos eran reclutados para empleos no calificados. Dado que muchos tienen habilidades vocacionales, frecuentemente implica una devaluación de su capacitación. Esto se aplica en particular cuando el traslado se hace de manera irregular, como sucede entre México y Estados Unidos. Más recientemente se ha dado una tendencia hacia la migración con más alta calificación desde estos países, aunque todavía es relativamente baja en comparación con la migración de baja capacitación.

La reunificación familiar comprende una porción creciente de la emigración. En Europa, el establecimiento no planeado y la reunificación familiar, desde los años setenta, llevaron a una normalización demográfica de las poblaciones turca y marroquí. En la actualidad, como señala el texto sobre Turquía, buena parte de la migración es con el propósito de formación familiar en vez de reunificación, ya que los migrantes de la segunda generación de origen turco y marroquí buscan cónyuges en su tierra ancestral. En el caso mexicano, el aumento del rigor en el control fronterizo por la «operación guar- 
dián» (Operation Gatekeeper), desde 1994, convirtió a muchos trabajadores inmigrantes temporales indocumentados en personas que se establecerían permanentemente y que llevarían consigo a sus cónyuges e hijos. La mayor parte de los migrantes altamente calificados se trasladan a través de categorías migratorias especiales que conceden derechos privilegiados para la reunificación familiar. Esto no se aplica a los de menor capacitación y la mayoría de los trabajadores indios y filipinos, en el Golfo o en los países asiáticos recientemente industrializados, no tienen oportunidad de llevar a sus familias.

\section{Sexo}

Las migraciones turca y marroquí de trabajadores huéspedes hacia Europa, en los años sesenta y setenta, estaban formadas predominantemente por varones (el estudio de Turquía menciona el 80\%), pero siempre algunas mujeres eran reclutadas como trabajadoras, por ejemplo, para las industrias del vestido y procesamiento de alimentos. Igualmente, buena parte de la migración marroquí actual hacia el sur de Europa, así como la migración india y filipina hacia el Golfo, es predominantemente masculina. En todos los casos, empero, la migración laboral femenina se ha incrementado, en parte por la creciente demanda de mano de obra en ocupaciones donde prevalecen las mujeres, como el trabajo doméstico, enfermería y otros cuidados además del entretenimiento. Parte de la migración femenina adopta la forma abusiva del tráfico para la industria del sexo. La migración de Filipinas se ha tornado altamente feminizada y las mujeres constituyen la mayoría de la nueva migración laboral. Para todos estos países, los traslados por la reunificación familiar, de mujeres y niños, aportaron para normalizar los saldos por sexo dentro de las poblaciones migrantes.

\section{Migración documentada e indocumentada}

La migración indocumentada, también llamada irregular o ilegal, parece estar en aumento, debido a la combinación de controles más estrictos y la continua demanda de mano de obra en los países receptores. La mayor parte de los flujos de mano de obra se han iniciado por medio del reclutamiento por parte de los gobiernos, patrones y agencias, circunstancia que se aplica, históricamente, a los trabajadores huéspedes turcos y marroquíes, a los trabajadores de escasa capacitación indios y filipinos e incluso a los braceros mexicanos. En todos estos casos, con excepción de la migración laboral asiática hacia el Golfo, la abolición de los sistemas de reclutamiento legal por los gobiernos de Estados Unidos y de Europa occidental condujo a procesos duraderos de migración indocumentada. Los nuevos flujos migratorios desde el norte de África hacia el sur de Europa han sido, básicamente, espontáneos e indocumentados, frecuentemente seguidos de legalización vía amnistías. La migración de trabajadores altamente calificados, por otro lado, es principalmente documentada, debido a la competencia internacional por el escaso capital humano. 


\section{Situaciones en los países de recepción}

Aunque los artículos dedicados a los países se ocupan, principalmente, de la emigración y el desarrollo, también dan información sobre la situación de los migrantes en los países receptores. Los trabajadores indios altamente calificados gozan de altos estándares de vida en los países occidentales y en el Golfo. Algunas veces, esto corre paralelo con un gran prestigio social, pero ello no siempre es así, ya que los profesionistas indios pueden ser sujetos de discriminación con base en sus orígenes nacionales o su raza. Es difícil generalizar acerca de los filipinos por su amplia difusión y diversidad. En particular, las mujeres experimentan explotación y abuso en el trabajo doméstico y en sectores similares. Es frecuente que los marineros perciban bajos salarios y en malas condiciones. Los marroquíes en Europa están sujetos a un estatus socioeconómico bajo, condiciones precarias y exclusión social. Por otro lado, se han convertido en un factor económico y social significativo en Holanda y en Francia. Lo mismo sucede con los mexicanos en Estados Unidos.

El artículo sobre Turquía es el más detallado. Descubre, predominantemente, un estatus socioeconómico bajo y altas tasas de desempleo, así como un creciente autoempleo en Holanda y Alemania. El logro educativo es bajo en promedio, pero muestra ciertas tendencias hacia la mejoría en la segunda generación. Los turcos en Alemania y Holanda experimentan altos niveles de segregación residencial y exclusión social. En general, hay marcadas evidencias de vínculos entre etnicidad y clase, de tal modo que muchos turcos pueden verse como parte de un estrato social bajo doblemente estigmatizado. La práctica de la segunda generación de inmigrantes, en el sentido de buscar pareja con propósitos matrimoniales en el país de origen, parece reforzar los temores a la «no integración» por parte de las poblaciones receptoras. Esos temores han estado ligados con las nuevas preocupaciones por la seguridad, después de los ataques fundamentalistas islámicos, por los cuales todos los musulmanes han llegado a ser vistos con suspicacia por parte de los Estados receptores. ${ }^{4}$

\section{Transiciones migratorias}

Como se muestra en la tabla 1, los cinco países de emigración, por lo general, no se sitúan entre los más pobres del mundo. México ha alcanzado el grupo, según los criterios

\footnotetext{
${ }^{4}$ En general, hay una crisis difundida en lo que concierne a las políticas de integración de todo tipo en Europa: las políticas asimilacionistas francesas han generado altos niveles de segregación y exclusión de los jóvenes de la segunda generación, lo que condujo a los amplios desórdenes de otoño de 2005; el multiculturalismo británico no logró la igualdad socioeconómica para los jóvenes originarios del sur de Asia ni logró evitar la alienación que subyacía a los bombazos del 7 de julio de 2005. Holanda abandonó una larga tradición de tolerancia cultural para adoptar medidas draconianas para el control de los ingresos y para obligar, a los inmigrantes, a conformarse a los valores holandeses. En Suecia hay segregación residencial así como altos niveles de desempleo de los inmigrantes, a pesar de su altamente desarrollado sistema de beneficencia social.
} 
del Banco Mundial, de ingreso «medio-superior», mientras que Turquía, Marruecos y Filipinas se ubican en el grupo de países de ingreso «medio-bajo». Sólo India es considerada un país de «bajo ingreso», pero no es parte de los países muy pobres con ingresos per cápita de menos de $\$ 500$ dólares americanos al año (la mayoría de los cuales se ubican en África subsahariana). Son número fríos que nada dicen de la distribución del ingreso (que es bastante desigual en todos los países), pero sí reflejan el hecho de que los migrantes provienen, principalmente, de países que ya están enganchados en un proceso de transformación económica y social.

TABLA 1

Ingreso nacional bruto (INB) per cápita 2005

\begin{tabular}{|c|c|c|c|}
\hline PAÍs & $\begin{array}{c}\text { RANGO (ENTRE 208 } \\
\text { PAÍ́SES Y TERRITORIOS) }\end{array}$ & $\begin{array}{c}\text { INB PER CÁPITA EN } \\
\text { DÓLARES DE EUA }\end{array}$ & $\begin{array}{c}\text { GRUPO DE INGRESO SEGÚN } \\
\text { EL BANCO MUNDIAL }\end{array}$ \\
\hline México & 71 & 7,310 & Medio-alto \\
\hline Turquía & 86 & 4,710 & Medio-bajo \\
\hline Marruecos & 129 & 1,730 & Medio-bajo \\
\hline Filipinas & 138 & 1,300 & Medio-bajo \\
\hline La India & 159 & 720 & Bajo \\
\hline
\end{tabular}

Fuente: (Banco Mundial, 2006b).

Nota: Esta tabla se basa en «Metodología del Atlas» del Banco Mundial. Para explicaciones de ésta y la alternativa de «Metodología de poder adquisitivo», véase el documento original.

La migración ha sido, a la vez, la consecuencia y la causa de esos cambios. Los científicos sociales han planteado la noción de una «transición migratoria» para analizar esas transformaciones (Zelinsky, 1971). ${ }^{5}$ Según esta teoría, al comienzo del proceso de modernización e industrialización suele haber un incremento en la emigración, debido al crecimiento poblacional, un descenso en el empleo rural y niveles salariales bajos. Tal fue el caso en Gran Bretaña a principios del siglo xix, así como sucediera, a fines de ese siglo, en Japón, o en Corea en los años setenta. A medida que avanza la industrialización decae la oferta de mano de obra y aumentan los niveles internos en los salarios, como consecuencia, baja la emigración y comienza a darse la inmigración de mano de obra. De tal modo que los países industrializados tienden a iniciar con una etapa de emigración, para pasar a una etapa de flujos de entrada y salida hasta que, finalmente, se da una transición para convertirse en un país en el que predomina la inmigración (Martin et al., 1996: 171-2). Un concepto más reciente, utilizado para describir este patrón, es el de la «joroba migratoria»: una gráfica de emigración muestra una línea ascendente, a medida que se da el despegue económico, luego se da una curva plana, seguida, en el largo plazo, por una caída a medida que surge una economía industrial más madura (Martin y Taylor, 2001).

\footnotetext{
${ }^{5}$ Véase también el artículo sobre Marruecos, por Hein de Haas, en este volumen.
} 
La evidencia de nuestros cinco casos de estudio plantea algunas dudas en torno a la validez de esas teorías generales de etapas de evolución. En realidad, los cambios parecen darse a través de trayectorias más complejas y tener efectos desiguales en diferentes sectores. En India, el cambio económico muestra un marcado dualismo: el surgimiento del sector de alta tecnología parece haber tenido un escaso efecto en la mayoría rural empobrecida, pues ésta todavía no experimenta un desarrollo económico de base amplia. La emigración es demasiado baja, en relación con la población, como para tener efectos marcados. India cuenta con cierta inmigración, tanto de trabajadores altamente calificados y escasamente capacitados, como de refugiados y migrantes irregulares procedentes de Nepal, Tíbet y Bangladesh, la que se ha acumulado en números suficientes como para causar, con frecuencia, algunas preocupaciones sociales y políticas. También Filipinas, en ausencia de un desarrollo económico rápido y sostenido, sigue siendo, de manera preponderante, un país de emigración. La experiencia mexicana muestra que la emigración masiva de mano de obra no necesariamente contribuye, en absoluto, al desarrollo económico del país de origen. Tanto las remesas como el crecimiento de la industria maquiladora parecen tener más efectos en la profundización de la dependencia mexicana, respecto a Estados Unidos, que para generar un desarrollo genuino. México tiene una creciente migración de tránsito, principalmente de centroamericanos y caribeños que buscan ingresar a Estados Unidos a través de México. Algunos de ellos se quedan en México, pero la emigración sigue siendo el tipo dominante de flujo, parece demasiado pronto para hablar de una transición migratoria.

Marruecos experimenta un cambio en sus patrones migratorios, esto refleja la mejora en el desempeño económico y en la forma de gobierno. La emigración permanece alta, pero la migración de tránsito de los africanos subsaharianos, que pretenden entrar a Europa, ha crecido rápidamente. Grandes cantidades quedan estancadas: al fracasar en sus intentos por llegar a España o Italia, y sin posibilidades de regresar a su terruño, permanecen en Marruecos. Además, una cifra creciente de migrantes subsaharianos muestran interés en buscar oportunidades en el norte de África (por ejemplo, en Libia, Egipto o en el mismo Marruecos). Los migrantes subsaharianos que permanecen en Marruecos son considerados ilegales por las autoridades y es frecuente que su situación sea muy pobre, aunque algunos se las arreglan para encontrar nichos en la economía informal. El desarrollo económico se encuentra todavía en una etapa temprana y la cifra de inmigrantes a largo plazo todavía es demasiado pequeña, para sacar conclusiones definitivas acerca de una transición migratoria todavía pendiente.

Turquía parece acercarse más al modelo de la transición migratoria. La emigración ha descendido notablemente, la migración de tránsito - tanto económica como forzada - se ha incrementado y, Turquía, se ha convertido en un destino para los migrantes económicos provenientes de los países del este de Europa y los antiguos países soviéticos (incluidos Moldavia, Georgia, Armenia y Bulgaria). Sin embargo, no hay evidencia de que la migración misma haya sido un factor que impulsara este cambio. Sin duda alguna, los intentos por asegurar las remesas de los migrantes y sus inversiones orientadas al crecimiento industrial, en los años setenta y ochenta, muestran las limitaciones de las ideas del desarrollo basado en las remesas. Parece que la secuencia causal 
es en el sentido inverso. La reforma política, la modernización institucional, los cambios demográficos y las transformaciones sociales han generado las condiciones para el crecimiento económico. En vez de una transición demográfica, parece darse un proceso de desarrollo generado desde el interior, lo que ha reducido la presión para emigrar.

\section{EL ESTADO Y LA EMIGRACIÓN}

Todos los estudios de caso por país prestaron considerable atención al papel que desempeñan los Estados de los países de origen. Plantean preguntas como: ¿en qué grado la emigración ha sido conducida por el Estado?, y, ¿qué tanto hacen los Estados, en la actualidad, para administrar la emigración y proteger a sus ciudadanos en el extranjero? Al comparar estos hallazgos es importante recordar que un aspecto del subdesarrollo es la limitada autonomía de los Estados del sur respecto a sus poderosas contrapartes del norte. Ello se muestra en el nivel general por medio de la imposición de políticas de ajuste estructural en muchos Estados del sur para regular la migración y, más específicamente, en el campo de la migración debido al superávit de trabajadores escasamente calificados en los mercados laborales mundiales.

\section{Políticas de emigración}

En cuatro de los cinco países, el Estado desempeñó un papel decisivo al comenzar la exportación de mano de obra: Marruecos y Turquía trabajaron con las autoridades de los países receptores, en los años sesenta y setenta, para organizar el reclutamiento, seleccionar a los trabajadores y asegurar el control político. Las motivaciones se centraban en exportar tanto el desempleo como la disidencia política y asegurar las remesas y habilidades para el desarrollo futuro. El gobierno filipino, bajo el presidente Marcos, inició también una política de exportación de mano de obra por razones similares, aunque quizá más con el objetivo de compensar la falta de desarrollo nacional que para procurarlo. El Estado mexicano trabajó con su contraparte estadounidense para llevar a cabo el Programa Bracero. Cuando el gobierno de Estados Unidos detuvo unilateralmente este programa, México, según señala el estudio referente a este país, se ubicó en una «política de no-política» que implicó quedarse a la expectativa mientras crecía la migración indocumentada. En contraste, India no tenía una política de empleo en el extranjero al comenzar la migración reciente.

En épocas más recientes, todos los Estados parecen haber cambiado hacia lo que el artículo sobre India llama un «paradigma de desarrollo». Esto equivale a enfatizar los beneficios de las remesas y otros efectos deseados de la migración, como la transferencia de habilidades y la búsqueda de maneras de maximizarlos. Cuando la emigración es muy considerable, puede verse como un factor crucial en la economía social. En el caso de México, esta visión ha adoptado la forma de una política de «desarrollo basado en las remesas», en la que la exportación de mano de obra se ha convertido en el centro de una 
estrategia para el «desarrollo nacional». El gobierno filipino también ve la exportación de mano de obra como un aspecto crucial y duradero de su política económica y busca maximizarla. El resultado de treinta años de sistemática exportación de mano de obra parece ser una falta de industrialización y de crecimiento económico, lo que es particularmente notable en vista de la experiencia mucho más positiva de economías bastante similares en el sureste de Asia, como Malasia y Tailandia.

\section{Instituciones}

Con la percepción de la creciente importancia nacional de la emigración, los Estados han creado instituciones para administrarla. En 2004, India estableció un ministerio para los asuntos indios en el extranjero (Ministry of Overseas Indian Affaires -MOIA), que incorporó el ya longevo protectorado de los emigrantes. Se estableció un fondo de bienestar para los trabajadores indios en el extranjero, mientras que el Departamento de Educación reservó lugares y becas en las universidades para los NRI's (Non-Resident Indians o ciudadanos indios residentes en el extranjero) y los PIo's (Persons of Indian Origin o personas cuyos padres o abuelos son de origen indio, pero que cambiaron su nacionalidad india por la de su país de residencia, abandonando su nacionalidad original). México estableció un Instituto de los Mexicanos en el Exterior, dentro de su Secretaría de Relaciones Exteriores, para fortalecer los lazos de los emigrantes con su terruño, así como apoyar los programas de educación y salud.

Hasta la década de los ochenta, el gobierno marroquí se preocupaba, principalmente, por mantener el control político sobre sus trabajadores en el extranjero, por ejemplo, al evitar que se unieran a los sindicatos franceses de izquierda. Los consulados marroquíes trabajaban con el servicio secreto para establecer asociaciones de migrantes conocidas como «amicales». Las políticas cambiaron en 1990, con el establecimiento de un Ministerio para los Marroquíes en el Extranjero (incorporado, en 1997, en el Ministerio de Asuntos Exteriores). La Fundación Hassan in se creó para apoyar las actividades culturales y sociales entre los migrantes, mientras que el Banco Al Amal fue creado para animar las inversiones y los proyectos económicos de los migrantes. Turquía estableció Diyanet, una institución del gobierno responsable de los asuntos religiosos, mientras que el Ministerio de Trabajo y Seguridad Social estableció la Dirección General de Relaciones Externas y Servicios para los Trabajadores en el Extranjero.

El gobierno de Filipinas diseñó una amplia estructura institucional para administrar la emigración. La Administración del Bienestar de los Trabajadores en el Extranjero (Overseas Workers Welfare Administration -owwA) se estableció en 1977, para promover el bienestar de los migrantes y sus familias que se quedaban en el terruño. Una Comisión para los Filipinos en el Exterior (CFO) se estableció en 1980, para promover los intereses y el bienestar de los emigrantes, y fue transferida de asuntos exteriores a la oficina del presidente, en 2004. Su propósito es alimentar los lazos entre los emigrantes y Filipinas, entre otras tareas, administra el LINKapIL (Link for Philippine Development, Vínculo para el Desarrollo Filipino). Una tercera institución de importancia es la 
Administración Filipina de Empleo en el Extranjero (Philippine Overseas Employment Administration -POEA), dentro del Departamento del Trabajo, que recluta y selecciona TCE's, asimismo, procesa sus documentos y contratos y les ofrece cursos de orientación previos a la emigración. También es responsable de conceder licencias así como de regular las agencias de reclutamiento y ubicación.

\section{Protección de los ciudadanos en tránsito y en el extranjero}

Es frecuente que los trabajadores de alta capacitación requieran de escasa protección, ya que la posesión de capital humano da cierta capacidad de negociación en los mercados internacionales de mano de obra, así como acceso a servicios legales profesionales. Esta situación es muy distinta para los trabajadores con escasa capacitación: un exceso en la oferta de quienes buscan empleo pone el poder del mercado en manos de los gobiernos y los patronos en los países importadores de mano de obra. No obstante, los gobiernos de los países de origen adoptan medidas para tratar de proteger a sus ciudadanos en el extranjero, con frecuencia en respuesta a la presión por parte de las asociaciones de migrantes y de otras organizaciones de la sociedad civil. Por ejemplo, el Decreto sobre Trabajadores Filipinos Migrantes y en el Extranjero (Migrant Workers and Overseas Filipino Act), de 1995, fue resultado directo de la movilización política por el caso de Flor Contemplación. Esta ley, diseñada para proteger a los filipinos en el extranjero, la sintetiza Assis (en este volumen). Otros países de origen también han promovido medidas legales como el registro y la regulación de agentes (como en India) y han dado algunos pasos para evitar el tráfico y explotación de mujeres y niños. México estableció un servicio llamado Grupo Beta para proteger a los migrantes, principalmente indocumentados, de las actividades criminales cuando tratan de cruzar la frontera; ello incluye actividades de rescate en cooperación con la policía a ambos lados de la frontera. México también tiene un Programa Paisano para «paliar el trato abusivo, la extorsión, el robo y otras formas de corrupción ejercidas por las autoridades públicas cuando los migrantes mexicanos regresan a su nación» (Delgado Wise y Márquez Covarrubias, en este volumen).

El problema más abrumador, para los Estados de origen de la migración, es establecer medidas efectivas para proteger a sus trabajadores en el extranjero. Por lo general, es ésta la obligación de los departamentos de asuntos exteriores, los que nombran agregados para el tema laboral y a funcionarios para el bienestar en sus consulados ubicados en los países importadores de mano de obra. No obstante, su capacidad de apoyar a los trabajadores en disputa con los patrones, o en alguna dificultad de otro tipo, se limita por la muy frecuente falta de disposición de las autoridades, en los países receptores, para cooperar. Entre otras limitaciones se incluyen la escasez de recursos, la falta de capacitación y la distancia social así como la desconfianza entre los funcionarios y los trabajadores migrantes. 


\section{Instrumentos legales internacionales}

Durante el periodo de los trabajadores huéspedes, se estableció una serie de acuerdos bilaterales entre los Estados que reclutaban mano de obra y aquellos desde los que salía ésta: por ejemplo, Alemania y Holanda con Turquía y Marruecos. Esos acuerdos regulaban el reclutamiento, condiciones de empleo y acceso a la seguridad social. Aunque con frecuencia limitaban en grado sumo los derechos de los trabajadores, en cambio sí reconocían a éstos un estatus legal en cuanto a su residencia y empleo, además de cierta protección. Esos acuerdos fueron finiquitados unilateralmente por los Estados receptores entre 1973 y 1974. En las oleadas más recientes de migración laboral, los Estados receptores han rechazado por completo ese tipo de acuerdos, aparentemente porque no veían la necesidad de hacer concesiones, a los trabajadores migrantes y a sus países de origen, en lo que se refiere a derechos y acceso a servicios. ${ }^{6}$

También se han hecho intentos para que entren en vigor instrumentos legales internacionales para salvaguardar los derechos de los trabajadores migrantes. Los más importantes son las convenciones número 97, de 1949, y la número 143, de 1975, de la Organización Mundial del Trabajo (OIT), y la convención de las Naciones Unidas sobre Derechos de los Trabajadores Migrantes y sus Familiares, de 1990. Estos instrumentos podrían lograr mucho para mejorar la situación de los migrantes, en cada etapa del proceso migratorio, si los Estados estuvieran dispuestos a firmarlos y ponerlos en práctica. Desafortunadamente, no es ése el caso. El instrumento más importante, la convención de las Naciones Unidas de 1990, no entró en vigor sino a partir de 2003, debido a que pocos Estados estaban dispuestos a ratificarlo. Todavía, en la actualidad, tan sólo 34 Estados lo han firmado, casi exclusivamente países de emigración. La resistencia a avanzar hacia una forma global de manejo de la migración, se debe, esencialmente, al temor de los países reclutadores de mano de obra de que la regulación incremente los costos de la fuerza de trabajo migrante e imponga obligaciones en los países receptores.

\section{Reconocimiento de la diáspora}

Con la progresiva conciencia de la contribución económica potencial de los emigrantes, las actitudes gubernamentales y públicas se han modificado. En el pasado, los emigrantes solían percibirse como personas que abandonaban su país de origen al irse a trabajar a otro lugar. En la actualidad, se les ha redefinido como «ángeles del desarrollo» (India) o como bagung bayani, los nuevos héroes del país (Filipinas). El gobierno marroquí habla ahora de «residentes marroquíes en el extranjero» y se dispone a «cortejar a la diáspora». Los migrantes indios y sus descendientes son vistos como «ciudadanos transnacionales

${ }^{6}$ Se han dado algunas excepciones, las más significativas son los programas, bastante limitados en el tiempo, de trabajadores migrantes comenzados en Alemania desde principios de los años noventa (véase Castles, 2006). 
o globales». En 2003, el gobierno turco nombró una comisión parlamentaria para que reportara en torno a los turcos en el extranjero y, actualmente, afirma que la integración en las sociedades receptoras no es incompatible con la identidad nacional turca. Las medidas de Filipinas para fortalecer el reconocimiento simbólico de los emigrantes incluyen visitas presidenciales a las comunidades en el extranjero, la celebración de «días de los trabajadores migrantes», la introducción de Balikbayan para hacer acreedores a derechos especiales (por ejemplo, en los traspasos de fondos, importación de bienes, reducción en los aranceles de importación) a los filipinos que residen en el extranjero, un concurso de belleza de «Señorita Filipinas en el extranjero» abierto a las jóvenes de origen filipino, incluso si éstas han dejado de ser ciudadanas (véase Asis en este volumen y Aguilar, 1999). No queda claro cuál es la visión de los propios migrantes respecto a esta repentina mejoría en su prestigio. En el pasado, muchos migrantes han desconfiado bastante del Estado, en especial en los casos en que regímenes autoritarios han intentado controlar las actividades políticas y de sus sindicatos. La creciente cooperación entre las asociaciones de migrantes y los Estados parece indicar cambios en ambos lados.

\section{Derechos para los ciudadanos en el extranjero}

La manera más significativa de reconocer a la diáspora es incluirla en los procesos políticos internos por medio de la doble ciudadanía y permitir el voto de los nacionales en el extranjero. Los cinco países muestran una tendencia en esa dirección. En 2006, India aprobó el derecho a la doble ciudadanía para los PIo’s en todos los países, con excepción de Pakistán y Bangladesh (ello debido a razones históricas vinculadas con la partición de India después de 1947). También se aprobó el derecho al voto para los indios en el extranjero. Khadria (en este volumen) señala que la doble ciudadanía es relevante sobre todo para los emigrantes con alta capacitación en Estados Unidos, Canadá, Australia o Reino Unido que se hacen ciudadanos de esos países, mientras que los derechos al voto desde el extranjero son más significativos para los trabajadores indios de menor capacitación en el Golfo.

México aprobó la doble nacionalidad para los mexicanos en el extranjero en 1996, pero ello no incluía derechos electorales. Esos derechos se aprobaron para las elecciones presidenciales de 2006, con cláusulas para el voto postal desde el extranjero. Sin embargo, parece que relativamente pocos de los votantes potenciales, estimados en 4.5 millones, acabarían por registrarse, de hecho, para la elección presidencial de 2006. Ello podría haber inclinado la balanza de manera decisiva, pero no queda claro si la falta de ciudadanos empadronados se debió a obstáculos burocráticos o a otros factores. El rey de Marruecos anunció, en 2005, que desde ese momento los migrantes podrían votar y ser votados para el parlamento. Se estableció un Consejo para los Marroquíes en el Extranjero para asesorar al gobierno. El gobierno filipino aprobó la doble ciudadanía y el derecho a votar para los filipinos en el extranjero en 2003.

El caso de Turquía es más complicado debido a la concentración de emigrantes en Alemania, un país receptor que todavía no se muestra dispuesto a aceptar la doble 
ciudadanía. Una reforma a la ley de nacionalidad en 1981 permitía la doble ciudadanía, pero la mayor parte de los turcos en el extranjero no pudo aprovechar la medida por las restricciones en Alemania. En respuesta se dieron cambios posteriores a la ley de nacionalidad en 1995: una «tarjeta rosa» se puso en práctica para conceder un «estatus privilegiado de no ciudadano» a los turcos que habían estado en el extranjero, estatus que incluía derechos a la propiedad y a tener empresas en Turquía, pero no al voto.

\section{Asociaciones de migrantes}

En el contexto de los esfuerzos del Estado por reconocer las diásporas y fortalecer su participación en el desarrollo nacional, las asociaciones de migrantes han asumido una renovada importancia. Sus papeles pueden variar dependiendo de las circunstancias:

- Apoyar y auxiliar a los migrantes, tanto durante la emigración como al retorno.

- Movilizar a los migrantes para realizar campañas para el mejoramiento de sus derechos y condiciones, así como en contra de medidas represivas o discriminatorias.

- Trabajar con los Estados para reforzar la contribución de las diásporas y de los retornados al desarrollo.

En los cinco artículos dedicados a los países, se enfatizan principalmente estos últimos tres roles, aunque no se dejan pasar por alto algunos otros. El artículo de India describe la proliferación de asociaciones, en especial entre los migrantes con alta capacitación laboral en Estados Unidos. Las asociaciones indias en el extranjero se basan en criterios regionales, lingüísticos, de casta y religiosos. También existen asociaciones específicas por ocupación, para los profesionistas y estudiantes, para apoyar los esfuerzos orientados al desarrollo, así como organizaciones más amplias que pretenden vincular a todas las demás entre sí. Khadria (en este volumen) encuentra más de mil asociaciones indias con sede en Estados Unidos, algunas que, además, tienen ramificaciones en Canadá. Es posible encontrar asociaciones similares en Europa y en el Golfo. Algunas asociaciones establecen y administran escuelas para los hijos de los migrantes indios.

Las asociaciones de mexicanos son muy vigorosas en Estados Unidos. Muchas se establecen a partir de vínculos regionales o lingüísticos, mientras que otras están ligadas con sindicatos o agrupaciones religiosas. Las asociaciones de oriundos (hometown associations) son de especial trascendencia, se conforman por razones sociales y culturales, además de la ayuda mutua, y se han convertido, asimismo, en importantes actores del desarrollo, al recolectar dinero para invertirlo en proyectos comunitarios en el terruño. Delgado Wise y Márquez Covarrubias (en este volumen) hablan de «un nuevo sujeto social: el migrante colectivo». Señalan que existen 623 asociaciones de oriundos que cubren el $9 \%$ de los emigrantes. Llaman también la atención hacia los activos medios mexicanos de comunicación en Estados Unidos, que incluyen a 300 estaciones de radio, 700 publicaciones periódicas y muchas estaciones de televisión. Estas asociaciones y las organizaciones mediáticas desempeñaron un importante papel en la movilización sin 
precedentes de los migrantes mexicanos en Estados Unidos, a principios del 2006, en contra de las propuestas de legislación diseñadas para reducir los derechos de los migrantes y militarizar, todavía más, la frontera entre México y Estados Unidos.

Las asociaciones de migrantes marroquíes han aumentado, de manera significativa, en años recientes, reflejando la tendencia general a la liberalización política y al surgimiento de una sociedad civil más vigorosa. Avci y Kirisci (en este volumen) señalan la reciente expansión de las asociaciones marroquíes en Holanda, país en el que existe una asociación marroquí por cada 462 personas de dicho origen. Las asociaciones Migrations et Développement, patrocinadas por el gobierno, son cada vez más significativas en Francia y Marruecos.

Filipinas tiene un fuerte sector de la sociedad civil, con muchas organizaciones no gubernamentales vinculadas con la Iglesia, los sindicatos y los partidos políticos. Los grupos defensores ligados con la migración parecen tener una influencia significativa en el Estado filipino, mientras que las asociaciones que se ocupan del bienestar, los derechos de los migrantes y los temas de las mujeres son importantes entre las poblaciones de migrantes filipinos.

Las asociaciones de migrantes turcos son numerosas, pero también muy diversas y reflejan divisiones políticas, religiosas, generacionales y sociales en Turquía y dentro de las poblaciones migrantes. Avci y Kirisci (en este volumen) afirman que las asociaciones turcas suelen tener muy distintas actitudes en asuntos religiosos y políticos que remiten al terruño, aunque igualmente trabajan en coordinación en los temas vinculados con las condiciones o políticas en el país de destino. En Holanda existe una asociación por cada 291 residentes turcos, al tiempo que la televisión y los medios impresos también tienen una importante presencia. La fuerza de los grupos turcos parece deberse, en parte, a las políticas gubernamentales que apoyan a las asociaciones minoritarias. Por otro lado, las poblaciones en el lugar de destino algunas veces perciben, a las asociaciones de migrantes, como un signo de integración.

\section{MIGRACIÓN Y DESARROLLO}

Informes internacionales (GCIM, 2005) y nacionales (IDC, 2004) recientes subrayan los beneficios potenciales de la migración para el desarrollo, enfatizando, especialmente, el papel de las remesas económicas en la mejoría de las formas de sostenimiento, al incrementar la demanda y estimular la producción (véase Carling en este volumen). Se cree que otros beneficios importantes, para el desarrollo, son la transferencia de tecnología y el retorno de «remesas sociales» altamente calificadas — la transmisión de conocimientos y de actitudes afines al desarrollo hacia los países de origen por los migrantes y quienes retornan-. ${ }^{7}$ Los más recientes debates sobre los beneficios para el desarrollo que ofrece la

\footnotetext{
${ }^{7}$ Otras iniciativas en esta área incluyen a la reunión de altos funcionarios de 57 Estados africanos y europeos en Rabat, durante julio de 2006, que se centró en proponer políticas para mejorar el manejo de la migración por
} 
migración se centran en el rol de las diásporas como socios potenciales del desarrollo. Los cinco estudios de los países de origen examinan estos temas, señalando efectos positivos de la migración en el desarrollo, pero también apuntan los potenciales efectos negativos.

\section{Remesas económicas}

La transferencia, hacia el lugar de origen, de las ganancias y ahorros de los migrantes, por lo general, es vista como el más importante efecto positivo de la migración para los países de origen. Según la revisión que hace el Banco Mundial de los datos de 2004, India fue el principal receptor mundial de remesas, seguido por China y, después, México. Filipinas ocupaba el quinto lugar y Marruecos el décimo, mientras que Turquía no se encontraba entre los primeros veinte receptores (Banco Mundial, 2006a: 90).

TABLA 2

Remesas 2004

\begin{tabular}{|c|c|}
\hline PAÍ́S & REMESAS: MILES DE MILLONES DE DÓLARES EUA \\
\hline La India & 21.7 \\
\hline México & 18.1 \\
\hline Filipinas & 11.6 \\
\hline Marruecos & 4.2 \\
\hline Turquía & 1.7 \\
\hline
\end{tabular}

Fuente: Banco Mundial (2006a), a excepción de la cifra para Turquía, que se refiere a 2003 y proviene de Gamze y Kirisci (en este volumen).

Los estudios por país llaman la atención hacia lo significativo de las remesas, pero también a los problemas que suelen traer consigo. En el caso de India, las remesas implican una importante contribución a la balanza de pagos y al Producto Nacional Bruto (PNB) - 3\% en 2000 (Banco Mundial, 2006a: 128) —. En las áreas de origen de la migración, constituyen un factor primordial para la reducción de la pobreza. Por ejemplo, las remesas constituyen el 10\% del PNB en Kerala (Khadria en este volumen). Pero las remesas no necesariamente contribuyen al desarrollo: pueden llevar a consumo suntuario y de hecho minar el potencial para el desarrollo. Además, Khadria apunta que existen importantes huecos en el conocimiento acerca de los efectos de las remesas en el desarrollo.

También en México, las remesas se han incrementado con rapidez y contribuyen, de manera significativa, a la balanza de pagos. Se han tornado en un elemento vital para la estabilidad económica y social al mitigar la pobreza. Delgado Wise y Márquez Cova-

medio de la combinación de controles fronterizos más estrictos y ayuda para el desarrollo (Noll, 2006); además del Diálogo de Alto Nivel de la Asamblea General de la ONU sobre migración y desarrollo en Nueva York, en septiembre de 2006 (véase http://www.un.org/esa/population/hldmigration/). 
rrubias (en este volumen) perciben al modelo basado en las remesas como una «perversión de la idea del desarrollo que no ofrece perspectivas de futuro». La exportación de mano de obra mexicana a Estados Unidos, tanto directamente por la migración como indirectamente a través de la industria maquiladora, es importante para la reestructuración de la economía estadounidense, pero sólo incrementa la dependencia mexicana, sin contribuir a un cambio económico y social positivo en el lugar de origen.

El estudio marroquí señala, asimismo, el importante papel de las remesas en la balanza de pagos y para paliar la pobreza, haciendo notar que las remesas se utilizan sobre todo para el consumo más que para la inversión. Sin embargo, De Haas (en este volumen) argumenta que los avances en vivienda, salud y educación son vitales para mejorar la productividad laboral y pueden considerarse una forma indirecta de inversión productiva. Además, el crecimiento del turismo, de importancia para la economía de Marruecos, está vinculado con el retorno de los migrantes.

Las remesas a Turquía han decaído de un máximo de 4 mil millones de dólares estadounidenses en 1998 (cifra que cubría el 37\% del déficit comercial de Turquía) a 1.7 miles de millones de dólares estadounidenses en 2003 (cifra equivalente al 8\% del déficit comercial). La caída se debió a un descenso en la emigración y al establecimiento permanente de antiguos migrantes en Europa occidental. Esto no es de sorprender a la luz de la transición migratoria turca, mencionada antes. En los últimos cuarenta años, las remesas han contribuido a mejorar los ingresos en las regiones de emigración, pero los intentos del gobierno por utilizarlos en inversión industrial han fracasado en gran parte.

\section{Remesas sociales}

Las remesas sociales son definidas por Peggy Levitt como «las ideas, comportamientos, identidades y capital social que fluyen de las comunidades del país de origen a las del país de destino» (Levitt, 1998: 926). Las expectativas positivas de parte de los analistas y los diseñadores de políticas, en lo que se refiere al impacto de las remesas sociales, se basan en la teoría de la modernización de los años cincuenta, que afirmaba que la transferencia de los «valores occidentales» de racionalidad, individualismo y espíritu empresarial era crucial para el desarrollo. Sin embargo, las evaluaciones críticas, como la de Levitt y las que se presentan en nuestros estudios por país, muestran que las remesas sociales tienen consecuencias ambiguas. Si las historias optimistas llegan a la comunidad de origen, en el sentido de que son bajos los riesgos y considerables los beneficios de trasladarse a economías de mayores salarios, ello puede estimular a más personas a realizar el viaje. Esto conduce al desarrollo de una «cultura de la emigración» en la que pasar una temporada trabajando fuera se convierte en un «rito de paso» normal para los jóvenes. Los estudios de caso en México, Marruecos y Filipinas refieren este fenómeno. El otro lado de la moneda lo forman los efectos sobre la comunidad de origen. Los estudios de India, Marruecos y Turquía mencionan que la migración ha sido una fuerza para la transformación en las áreas de origen, por medio de la transferencia de actitudes que conducen al cambio y al desarrollo. Por otro lado, la ausencia de hombres 
y mujeres jóvenes, durante sus años más productivos, puede tener efectos negativos en el cambio social y el crecimiento económico. El estudio marroquí llama la atención a la transferencia de habilidades a través de los migrantes de retorno. Por supuesto que, como señala el estudio turco, cuando los migrantes se establecen en las áreas receptoras, o tan sólo regresan tras agotar sus periodos de vida productiva, este efecto se reduce.

\section{Movilizar la diáspora para favorecer el desarrollo}

La idea de que los gobiernos y las agencias internacionales deberían trabajar con las diásporas, para encontrar formas de fortalecer su capacidad y su actitud para el desarrollo, ha recibido mucha atención en los últimos tiempos (véase GCIM, 2005; IDC, 2004). Todos los gobiernos de los países de origen han tomado medidas para lograr estos propósitos.

El Ministerio para los Indios en el Extranjero apoya la red de conocimiento de la diáspora, diseñada para conectar a los emigrantes altamente calificados con oportunidades en su país de origen. México estableció un importante mecanismo para estimular las inversiones colectivas de los migrantes en proyectos comunitarios. El Programa Tres por Uno se estableció en 1999, con base en programas regionales fundados desde principios de los años noventa. El Programa Tres por Uno es administrado por la Secretaría de Desarrollo Social (sEDesol) del gobierno federal. ${ }^{8}$ Las transferencias de dinero, por parte de las asociaciones mexicanas de oriundos, son equiparadas por cantidades de dinero provenientes de los gobiernos municipal, estatal y federal. Los fondos se utilizan para proyectos de mejora de carreteras, agua potable, drenaje y electricidad. En 2004, más de 50 millones de dólares estadounidenses estuvieron disponibles por este canal. También existe el Programa Invierte en México, del Banco Interamericano de Desarrollo y Nacional Financiera. Marruecos estableció el Banque Al Amal, en 1989, para estimular la transferencia legal de remesas y apoyar los proyectos de los migrantes. En Filipinas, la Comisión para los Filipinos en el Extranjero apoya el LINKAPIL para movilizar los recursos de la diáspora.

En este renglón, Turquía también constituye una excepción. Tras el fracaso de los intentos por canalizar las remesas de los migrantes hacia la inversión industrial, en los años setenta (Hönekopp y Tayanç, 1998; Martin, 1991), el gobierno turco parece concentrarse ahora en los aspectos simbólicos y políticos. La diáspora es vista, principalmente, en términos de mantener la identidad nacional. El mecanismo para lograrlo es el apoyo estatal a las actividades religiosas, culturales y sociales. Una vez más, la diferencia parece estar ligada con la etapa de la transición migratoria a la que ha llegado Turquía. 


\section{DIFERENCIAS, SIMILITUDES Y CONVERGENCIA}

En este punto es posible regresar a las preguntas planteadas al principio del trabajo. El primer objetivo consistía en ver si los cinco países de emigración compartían características comunes significativas, de modo que los analistas, diseñadores de políticas y practicantes estuvieran en posibilidad de reflexionar a partir de la comparación. Una forma de responder es sintetizar las diferencias y similitudes en la experiencia de emigración en los cinco países y, luego, discutir el grado al cual se presentan convergencias en resultados, respuestas y políticas.

\section{Las fuerzas detrás de la migración}

Aunque el tamaño de la población es bastante diferente, todos los países comparten la característica de una transición demográfica tardía, lo que significa que cuentan con poblaciones en aumento y relativamente jóvenes. Sus economías no han crecido lo suficientemente rápido como para absorber a los muchos jóvenes de nuevo ingreso en el mercado laboral. Esto es consecuencia de un desarrollo económico estancado o desigual, lo que, a su vez, puede ligarse con el dominio colonial del pasado y, más recientemente, con la dominación económica por las corporaciones multinacionales, los Estados del norte y las instituciones financieras internacionales. En lo que se refiere a los factores políticos, los gobiernos de Marruecos y Filipinas utilizaban la emigración de mano de obra como una forma de quitarse de encima a las minorías étnicas o a los disidentes políticos. En el caso de Turquía, los activistas étnicos y políticos fueron forzados a protegerse de la persecución por medio de la huida del país. En años más recientes, India, Marruecos y Turquía han logrado avances considerables en despojarse de la dominación económica poscolonial, mientras que Filipinas ha tenido avances más limitados y México ha progresado muy poco en apariencia.

\section{Migración y transformación social}

A pesar de las diferencias en la situación geográfica y experiencia histórica, existen fuertes semejanzas en la economía política de la emigración. Por ello, es importante analizar la migración como parte del proceso de transformación social global que comenzara con la expansión colonial europea en el siglo xvi. La movilización del potencial de mano de obra de África, Asia y América Latina siempre ha sido parte de este proceso, sea en forma de esclavitud, trabajo por contrato o mano de obra forzada. La globalización, como la forma más reciente de transformación social, implica migración a gran escala para satisfacer las demandas económicas y, cada vez más, demográficas de las economías del norte. Ello puede implicar la integración en mercados regionales de mano de obra (en el caso de México, Marruecos y Turquía) o mercados globales de 
fuerza de trabajo (India y Filipinas). En ambos casos, una característica central es la diferenciación de los trabajadores, por medio de reglas y categorías de inmigración, según el capital humano de que dispongan, las habilidades o los orígenes étnicos y nacionales.

\section{Historia de la migración}

¿Qué hace que un país se convierta en un reservorio de mano de obra para los países desarrollados? La comparación de India, México, Marruecos y Filipinas muestra que se trata de la culminación de largos procesos históricos, en especial en el periodo colonial. Turquía es bastante diferente, dado que la emigración de mano de obra no comenzó sino hasta los años sesenta, como resultado de la cooperación entre los Estados alemán, holandés y turco. Sin embargo, la complementariedad entre la motivación económica y política de las elites, en los países de origen y destino, parece constituir un rasgo frecuente al principio de la migración laboral. Igualmente, encontramos convergencias en los patrones a largo plazo: una vez que comienzan, los movimientos migratorios tienden a autosustentarse, incluso cuando cambian las políticas de los gobiernos. Ello se debe no sólo a la demanda por parte de los patrones, sino también al desarrollo de redes migrantes, las que sirven de apoyo a la reunificación familiar y al establecimiento.

\section{Características de la migración}

Los patrones de migración han variado considerablemente en lo que respecta a volumen, tiempos, tipo de motivaciones (económica frente a forzada), patrones por sexo y distribución de habilidades. La emigración ha sido bastante considerable en relación con la población total en México, Marruecos y Filipinas - cerca del 10\% en cada caso- - Los cinco países se han convertido en proveedores de mano de obra para las ricas economías de Estados Unidos y Europa y, más recientemente, las economías industriales emergentes del este y el sureste asiáticos así como en los países petroleros del Golfo. En lo que se refiere a los niveles de capacitación, la migración india parece encuadrar en dos grandes grupos: migrantes altamente calificados en Estados Unidos, otros países desarrollados y algunos en el Golfo, y trabajadores menos calificados, principalmente en el Golfo. Los migrantes filipinos muestran un amplio rango de niveles de capacitación, mientras que los mexicanos, marroquíes y turcos se concentran en las ocupaciones de escasa calificación.

Los Estados diferencian entre migrantes y compiten por los de alta calificación, mientras que tratan de reducir los ingresos de los trabajadores escasamente calificados. Esto se refleja en las condiciones y estándares de vida. Los trabajadores altamente calificados, por lo general, gozan de buenos salarios y condiciones (aún cuando pueden experimentar cierto grado de discriminación y racismo). Los trabajadores migrantes menos calificados y sus familias tienen posiciones económicas, sociales y políticas más desven- 
tajosas en las sociedades receptoras. Es frecuente que esto se complique por la negación de una gama de derechos, incluso para los trabajadores huéspedes legales o THL. Los trabajadores indocumentados están mucho peor: se les niega permiso oficial para ingresar al país y para trabajar en él, pudiendo fácilmente ser explotados por los patrones.

La composición por género se ha tornado más equitativa, con cantidades crecientes de mujeres que migran, tanto en el papel de trabajadoras como en el de cónyuges. Las distribuciones por edad también se han ampliado, con un mayor número de niños y personas de edad avanzada en las poblaciones migrantes. Esta normalización demográfica está vinculada con la tendencia general al establecimiento a largo plazo o permanente. La migración para la formación de familias ha surgido entre los grupos de la segunda generación. Las políticas de gobierno afectan a los patrones migratorios, con frecuencia de maneras inesperadas. Detener el reclutamiento de trabajadores huéspedes en Europa y la militarización de la frontera entre Estados Unidos y México condujo a un aumento en la migración indocumentada y a un incremento en el establecimiento en los países receptores, exactamente lo contrario de lo que se proponía la política.

\section{Transiciones migratorias}

Según la teoría de la transición migratoria, la emigración se incrementa en las primeras etapas del desarrollo y sólo decae como consecuencia de cambios demográficos y económicos a largo plazo. Como muestran nuestros cinco casos de estudio, la migración y el desarrollo están vinculados de diversas maneras. Es frecuente que los procesos de desarrollo impulsados por los factores económicos, sociales y políticos internos sean los que cambien las condiciones y formas de la migración. Los 20 o 25 millones de indios que se estima están fuera de su país equivalen a menos del $2 \%$ de la población total y este volumen parece demasiado bajo como para contribuir a una transición migratoria. Filipinas tiene una considerable emigración, pero, en ausencia de otros factores necesarios para un desarrollo económico sostenido, no hay señales de una transición migratoria. En México es posible observar algunos elementos de una transición, con un incremento en la migración de paso y cierto establecimiento de inmigrantes, pero la dependencia económica todavía es bastante marcada. También Marruecos puede estar al borde de una transición migratoria, mientras que esta tendencia parece bastante avanzada en Turquía, impulsada por importantes cambios en la infraestructura y las instituciones.

\section{El Estado y la emigración}

En los casos de México, Marruecos, Filipinas y Turquía, el Estado desempeñó un papel fundamental para desencadenar la migración de mano de obra, frecuentemente con la cooperación de las autoridades de los países receptores. Algunos Estados vieron a la emigración como un instrumento potencial para el desarrollo, pero otros estaban más preocupados por exportar el desempleo y el disenso político. Más tarde, los paí- 
ses de emigración se orientaron hacia un paradigma de desarrollo que enfatizaba los beneficios de las remesas, la transferencia de tecnología y la «circulación de cerebros». También desarrollaron instituciones para regular a los reclutadores y las agencias, evitar el tráfico y el contrabando, preparar a los migrantes y protegerlos mientras estuvieran fuera del país. El alcance y la capacidad de esas instituciones varía considerablemente. Filipinas es el país que más ha avanzado en el desarrollo de un conjunto amplio de legislación y de agencias. Es dudosa la efectividad de las medidas para proteger a los migrantes, dado que las autoridades de los países de emigración no sólo carecen de recursos sino también del poder para exigir mejoras, por parte de los países receptores, en una época en que hay exceso global en la oferta de trabajadores poco calificados.

Una convergencia significativa se encuentra en la actitud de los Estados de los países de origen frente a sus nacionales en el extranjero. Al comienzo de la migración laboral, los emigrantes eran vistos como «población sobrante» o «generadores de problemas» de los que había que deshacerse. Mientras estaban en el exterior se les consideraba como amenazas potenciales a la patria. Los Estados turco y marroquí buscaban el control por medio de la supervisión política y del apoyo a las organizaciones patrióticas o religiosas. Desde los años ochenta se ha dado un cambio general. Los ciudadanos en el extranjero ahora son vistos como valiosas diásporas que pueden contribuir al desarrollo, conservar una fuerte identidad nacional y apoyar los intereses económicos y políticos de la antigua patria. Los migrantes han sido redefinidos como «héroes del desarrollo» y los gobiernos apoyan a las asociaciones políticas y culturales, los bancos de desarrollo y las redes diseñadas para "cortejar a la diáspora» (como se expresa en el estudio sobre Marruecos). Los cinco países han aprobado legislaciones para permitir la doble ciudadanía (o nacionalidad) para los nacionales en el extranjero y para concederles derechos electorales en el país de origen.

\section{Asociaciones de migrantes}

Reconocer a la diáspora significa trabajar con las asociaciones de migrantes. En este renglón también hay diversidad en el tamaño y composición de las membresías, en las filiaciones políticas y religiosas, los objetivos y los modos de organización. Una importante convergencia se da en la creciente fortaleza de las asociaciones de migrantes en los países de destino. Esto ha hecho de ellas un factor significativo en la política, tanto del país de recepción como en el de origen. Otra convergencia más se da en su disposición - ocasional- para trabajar independientemente de las divisiones sociales, políticas y religiosas y representar los intereses de los compañeros del mismo grupo étnico (o incluso de todos los migrantes), en confrontación con las instituciones o agrupaciones políticas del país receptor. No obstante, las movilizaciones masivas como la de los mexicanos en contra de las propuestas de legislación antiinmigrante en Estados Unidos, a principios de 2006, sólo surgen en circunstancias excepcionales. Una convergencia más se da en la creciente participación de las asociaciones de emigrantes en las iniciativas para el desarrollo de sus lugares de origen. 
La sección anterior abordó el primer objetivo de los estudios por país, al sintetizar la experiencia migratoria de cinco importantes países de emigración. La comparación revela importantes diferencias en los contextos social e histórico, los patrones de migración y los enfoques en las políticas de los cinco países, aunque también mostró muchas similitudes y, de manera por demás significativa, convergencias en importantes áreas. Un segundo objetivo de los estudios por país era examinar el grado al cual la migración contribuye, de hecho, al desarrollo.

Como se señaló antes, el más importante beneficio de la migración en el desarrollo se percibe, generalmente, en el rol de las remesas económicas para mejorar las formas de sostenimiento, incrementar la demanda y estimular la producción. Otros importantes beneficios en el desarrollo se perciben en la transferencia de tecnología y en el retorno de los trabajadores altamente calificados y en las «remesas sociales» (transferencia de conocimientos y actitudes novedosas por parte de las diásporas y los retornados). Los debates más recientes, acerca de los beneficios en el desarrollo que ofrece la migración, se centran en el papel de las diásporas como socios potenciales para el desarrollo.

En lo que respecta a las remesas económicas, los estudios por país muestran una diversidad de experiencias dentro de los países de origen y de estos entre sí. La lección general que se deriva de la comparación consiste en que las remesas no conducen automáticamente al desarrollo. Efectivamente, bajo ciertas circunstancias pueden derivar en consumo suntuario, tipos de inversión ineficientes y dependencia económica en la emigración continuada y algunas veces, incluso, ocultar un flujo invertido de fondos hacia los países desarrollados. La supuesta vinculación positiva entre las remesas y el desarrollo sólo se da si se ponen en práctica las políticas adecuadas para estimular las transferencias legales y la inversión productiva, para reducir la corrupción y la burocracia innecesaria, además de proporcionar una infraestructura que facilite la inversión. La experiencia con la transferencia tecnológica y el retorno de los trabajadores altamente calificados es bastante similar: los efectos positivos sólo se dan si cambian las estructuras y las oportunidades en los países de emigración, de tal modo que los emigrantes retornen antes de que agoten su vida productiva. Una condición previa adicional es que los trabajadores calificados puedan mejorar o, al menos, conservar sus credenciales mientras estén en el extranjero. Es frecuente que ése no sea el caso, dado que los migrantes calificados pueden emplearse en trabajos de baja capacitación.

Las remesas sociales también tienen efectos diversos. El mensaje que llega de parte de los emigrantes, a sus comunidades de origen, puede ser que las nuevas formas de trabajar, invertir y llevar los asuntos públicos acarrean prosperidad, pero también puede consistir en que la emigración es la única forma de salir de una situación desesperada. El surgimiento de la emigración como un «rito de paso» normal para los jóvenes puede conllevar a la pérdida no sólo de trabajadores productivos, sino también de agentes del cambio. Los costos sociales y económicos de la emigración pueden ser altos: los estu- 
dios por país llaman la atención a la tensión causada en las familias por la separación por largos periodos (como sucede con el síndrome de las «esposas del Golfo» en India); la distorsión de los sistemas de educación, remodelados para responder a las necesidades de los países de destino (lo que se menciona en los artículos sobre Filipinas e India); los riesgos y peligros con los que se topan los migrantes; la pérdida potencial de personas capacitadas y de recursos humanos que puede desembocar en estancamientos en el desarrollo (mencionados para México, Filipinas y Turquía), y la «desacumulación de la riqueza mexicana» y su transferencia a Estados Unidos. En general, la emigración de mano de obra - ya sea capacitada o sin capacitación - puede conducir a una severa pérdida en el potencial de crecimiento para el país de emigración. La pregunta es si esta pérdida puede ser compensada en el largo plazo por los efectos positivos.

El reconocimiento del papel de las diásporas en el desarrollo parece constituir un importante paso adelante. Este nuevo discurso, en el campo de la migración internacional, se da después de cambios en las percepciones en los países de emigración y de la introducción de una gama de medidas e instituciones para «cortejar a la diáspora». Aun cuando todos los estudios por país describen esos esfuerzos, todavía no hay datos suficientes ni evidencias derivadas de la investigación como para evaluar su grado de éxito. Las remesas colectivas para la inversión comunitaria, por parte de las asociaciones de oriundos y grupos similares, son aún bastante pequeñas en comparación con los flujos privados. Las redes de transferencia de conocimientos (como la Diaspora Knowledge Network existente en India o LINKAPIL en Filipinas), parecen positivas, pero bastante limitadas en comparación con las remesas individuales y las transferencias comerciales, que son motivadas por objetivos de desarrollo.

La conclusión general sobre la migración y el desarrollo es, por tanto, que hay necesidad de perspectivas de mayor alcance y a largo plazo que vinculen los beneficios potenciales de la migración con las estrategias más generales para reducir la desigualdad y mejorar la infraestructura económica, el bienestar social y las formas de gobierno en el ámbito político. Si se adoptan esas estrategias hay una buena posibilidad de que haya resultados favorables para las poblaciones de los países de origen, pero las condiciones para lograrlo son complejas y difíciles. Las estrategias del «desarrollo basado en las remesas» (como en México) parecen simplistas e ingenuas. La migración por sí sola no puede remover los obstáculos estructurales que estorban al crecimiento económico, al cambio social y a una mayor democracia.

En el caso mexicano, ello significaría una nueva aproximación a las relaciones económicas y políticas que subyacen a la integración asimétrica, de la economía y el mercado de trabajo de México, dentro de la esfera de control de Estados Unidos. Para Marruecos y Turquía significaría rechazar el traslado de la «frontera laboral» euromediterránea hacia el sur y el este, negándose a adoptar el papel de «estados de protección» (buffer) o de «territorios de desecho» de quienes solicitan asilo o de migrantes a los que se les niega la entrada a la UE. ${ }^{9}$ Para Filipinas implicaría abandonar la idea 
de ser el «productor de trabajadores para el mundo», idea que equivale a aceptar una subordinación permanente en la división internacional del trabajo. En vez de ello, se necesitan políticas que combinen la reforma política y económica, dentro del país, con el reconocimiento del papel potencial en el desarrollo que poseen la diáspora y los retornados. India es bastante diferente a este respecto, en el sentido de que la migración implica una aportación menor al cambio. De cualquier modo, las remesas y el retorno de personal altamente calificado son significativos y necesitan ser vinculados con metas económicas más amplias.

¿Qué significa todo ello para la cooperación sur-sur? Un propósito central de este taller fue explorar el terreno común entre los países de emigración y utilizarlo como el fundamento para sugerir estrategias para la cooperación sur-sur, por encima de las fronteras. Este tema no se exploró en detalle en los estudios por país ni lo haremos aquí. Al examinar las experiencias de cinco importantes países de emigración y establecer las importantes similitudes y convergencias entre ellos, los estudios por país y este trabajo comparativo fueron pensados para ofrecer una base para desarrollar estrategias y mecanismos para el trabajo conjunto. Esto se buscó en los debates posteriores a Bellagio y se refleja en el documento final: «Perspectivas desde el sur: Conclusiones sobre migración y desarrollo».

\section{BIBLIOGRAFÍA}

ADEPoJU, A. (2006), «Leading issues in international migration in sub-Saharan Africa», en C. Cross, D. Gelderblom, N. Roux, y J. Mafukidze (eds.), Views on Migration in Sub-Saharan Africa, HSRC Press, Ciudad del Cabo, pp. 25-47.

AGUilar, F.V.J. (1999), «The triumph of instrumental citizenship? Migrations, identities and the nation-state in Southeast Asia», Asian Studies Review 23:3, pp. 307-336.

Banco mundial (2006a), Global Economic Prospects 2006: Economic Implications of Remittances and Migration, Banco Mundial, Washington DC.

BANCo MUNDiAL (2006b), World Development Indicators Database: GNi per Capita, Banco Mundial, http://siteresources.worldbank.org/datastatistics/Resources/gnipc.pdf.

CASTLES, S. (2004), «The factors that make and unmake migration policy», International Migration Review 38:3, pp. 852-884.

CAstles, S. (2006), «Guestworkers in Europe: A Resurrection?», International Migration Review, en prensa.

CASTLES, S. (2007), «Twenty-first century migration as a challenge to sociology», Journal of Ethnic and Migration Studies 33, en prensa.

cohen, R. (1995), «Asian Indentured and Colonial Migration», en R. Cohen (ed.), The Cambridge Survey of World Migration, Cambridge University Press, Cambridge.

GCIM (2005), Migration in an Interconnected World: New Directions for Action: Report of the Global Commission on International Migration, Global Commission on International Migration, Ginebra, Octubre. 
HÖNeKopp, E. y Tayanç, T. (1998), «Releasing the development potential of return migration: the case of Turkey», en United Nations Working Group on International Migration (ed.), United Nations Technical Symposium on International Migration and Development, 29 June - 3 July 1998, La Haya, Holanda, inédito.

IDC (2004), Migration and Development: How to Make Migration work for Poverty Reduction, House of Commons International Development Committee, HC 79-II, Londres.

KRITZ, M.M., Lin, L.L. y Zlotnik, H. (1992), International Migration Systems: A Global Approach, Clarendon Press, Oxford.

LEViTT, P. (1998), «Social remittances: migration driven local-level forms of cultural diffusion», International Migration Review 32:4, pp. 926-48.

Martin, P., Mason, A. y Nagayama, T. (1996), «Introduction to special issue on the dynamics of labor migration in Asia», Asian and Pacific Migration Journal 5:2-3, pp. 163-73.

MARTIN, P.L. (1991), The Unfinished Story: Turkish Labour Migration to Western Europe, International Labour Office, Ginebra.

MARTIN, P.L. y Taylor, J.E. (2001), «Managing migration: the role of economic policies», en A.R. Zolberg y P.M. Benda (eds.), Global Migrants, Global Refugees: Problems and Solution, Berghahn, Nueva York y Oxford, pp. 95-120

NolL, G. (2006), The Euro-African Migration Conference: Africa sells out to Europe, Open Democracy, www.opendemocracy.net.

PORTES, A., Guarnizo, L.E. y Landolt, P. (1999), «The study of transnationalism: pitfalls and promise of an emergent research field», Ethnic and Racial Studies 22:2, pp. 217-237.

RoDney, W. (1972), How Europe Underdeveloped Africa, Bogle-L'Ouverture, Londres. UN Population Division (2006), International Migration 2006, United Nations Population Division, Nueva York, Octubre.

VERTOVEC, S. (2004), «Migrant transnationalism and modes of transformation», International Migration Review 38:3, pp. 970-1001.

ZELINSKY, W. (1971), «The hypothesis of the mobility transition», Geographical Review 61:2, pp. 219-49. 